\title{
EVALUATION OF THE EUCALYPTUS CAMALDULENSIS-KILLED CERCARIAE AS A CANDIDATE VACCINE FOR EXPERIMENTAL SCHISTOSOMIASIS MANSONI
}

\author{
By \\ REHAM MUSTAFA BRAKAT ${ }^{1 *}$, SHAIMAA SHERIF SOLIMAN ${ }^{2}$ \\ AND SHAIMAA AHMED SHARAF-EL-DEEN ${ }^{1}$ \\ Department of Parasitology ${ }^{1}$, and Department of Public Health and Community \\ Medicine $^{2}$, Faculty of Medicine, Menoufia University, Egypt \\ ( ${ }^{*}$ Correspondence: reham_brakat@yahoo.com Mobile: 00201004774422)
}

\begin{abstract}
Schistosomiasis is the second commonest parasitic disease worldwide. It is responsible for thousands of deaths per year in addition to the associating serious morbidities that burden both individuals and communities. To date, the main preventive measure of infection is mass treatment with praziquantel. it carries the risk of reinfection and rising resistance which makes the discovery of an effective vaccine an urgent necessity. The present study evaluated E. camaldulensis killed cercariae immunogen (KCI) as a candidate vaccine for experimental schistosomiasis mansoni and to detect the possible immunological mechanisms of action of this immunogen. The KCI caused a significant reduction of both schistosomula and adult worm counts with subsequent ova count reduction. Hepatic granulomas were reduced in number or size. Also, levels of IgG, IgG1 \& IgG2a as well as INF- $\gamma$ \& IL-10 fluctuated larger than in natural infection.
\end{abstract}

Key Words: Eucalyptus Camaldulensis, killed cercariae vaccine, Schistosoma mansoni

\section{Introduction}

Schistosomiasis is one of the most important neglected tropical diseases that affected more than 250 million people worldwide and responsible of over 11 thousand deaths per year (Leow et al, 2020). It is a disease of low socioeconomic individuals where most of cases are centered in Sub-Saharan Africa that shares by annual mortality of 280,000 individual (Anisuzzaman and Tsujic, 2020). The associating chronic morbidities causes up to 70 million disability-adjusted life years loss annually that reached up to 71 million individuals with higher incidence in adolescents, and women of reproductive age (Keitel et al, 2019).

Up to date, the control strategies for schistosomiasis mainly rely on mass praziquantel (PZQ) treatment that killed the adults. Schistosomes ranked the second most risky parasite after malaria. Infection was complicated by rapid and re-infections and development of PZQ resistant strains (Lotfy et al, 2015), which have genotoxic and carcinogenic effects. In low socioeconomic endemic countries, schistosomal drugs were expensive and massive treatment cost was high (Chitsulo et $a l$, 2000). These weak points necessitated the need for an effective schistosomiasis vaccine as a potentially means for disease control (Leow et al, 2020). But, the controversy was about the type of immune response that elicited an effective vaccine candidate for a satisfaction high degree of protection against schistosomiasis (Rofatto et al, 2013). Although Th1 immune profile characterized by an increase in IFN- $\gamma$ was effective in schistosomiasis prevention experimentally, a strong Th2 or a mixed Th1/Th2 response must be associated with a significant worm burden reduction (Dias et al, 2014).

Antigens retrieved from cercariae enhance both Th1 \& Th2 immune responses, but the schistosomula or adult worm-derived antigens usually induced predominant Th1 immune responses (El Ridi and Tallima, 2015).

Many cercarial antigens were studied as vaccine candidates and achieved different degrees of protection against challenge infections. The first was the crude cercarial antigen preparation (CAP) which was prepared from the supernatant fluids of buffered saline homogenates of cercariae (Ashour et $a l, 2004)$. Another type of cercarial vaccines 
was the attenuated cercariae. Various techniques were used for the attenuation e.g. heat, chemical, ultraviolet treatment, or ionizing radiation (Tebeje et al, 2016). All the techniques proved efficacy but radiationattenuated cercariae vaccine achieved the most effective results under laboratory conditions. These protective effects were tested in rodents and also extended to primates; a reduction of worm burden varying from $30 \%$ to $90 \%$ was achieved in challenge infections (El Ridi and Tallima, 2015). In spite of spite the good results, radiation of attenuated cercaria was still limited by many hindrances e.g. difficulty of dose calibration of ionizing radiation to attenuate cercariae, the requirement of cryopreservation to transport attenuated cercariae over long distances, the potential toxicity of administering a live vaccine (Shuxian et al, 1998), and cannot be used in humans for ethical and practical problems of radioactive materials (Kariuki et $a l$, 2006). So, it makes sense to reconsider killed cercarial vaccines even if they are less antigenic.

Despite their lower antigenicity, killed vaccines were more stable, safe, and cost less than attenuated ones (Strugnell et al, 2011). So, they were easily manufactured in low income endemic countries with relatively low technological skills (Rostamian et al, 2018). To avoid toxicity problems, it would be better if the killing agent is a safe natural product. Eucalyptus (E.) camadulensis is a medicinal plant that is used in various fields. Its essential oils are used in manufacturing soaps, detergents, lotions, perfumes and even food flavors (Carvalho et al, 2016). Besides, it proved many antimicrobial (Neelam et al, 2014) anti-inflammatory (Pino et al, 2002), larvicidal (Batish et al, 2008), mosquito-repellents (Nerio et al, 2010), and killed swimming cercariae (Ghareeb et al, 2018).

The present work was designed to answer three questions. Can immunization by $E$. $c a-$ maldulensis killed cercariae (KCV) protect mice from experimental schistosomiasis $m a-$ nsoni? What are the effects on schistosomu- la and adult stages? What are the immunological mechanisms of this immunogen?

\section{Materials and Methods}

Ethics statement: Male pathogen-free $\mathrm{BALB} / \mathrm{c}$ mice (6-8 weeks, 18-20gm) were used for the experiment. All the experiments were done at Theodor Bilharz Research Institute (TBRI), Giza. Mice were kept under standard housing conditions and standard commercial diet in the animal house of TBRI. Experimental procedures were performed in accordance with the international ethical guidelines after approval of the institutional ethical committee of TBRI.

Study Design: $60 \mathrm{BALB} / \mathrm{c}$ mice were divided into three groups; 20 mice each. GI: a negative control. GII: a positive control for $S$. mansoni. GIII: mice immunized by the killed cercariae immunogen (KCI). Each group was subdivided into 2 subgroups of 10 mice each. Subgroup A: mice euthanized 17 days after challenge infection for schistosomula studies, and subgroups B: mice euthanized 50 days after challenge infection for adult studies.

Plant Extraction Preparation: Leaves of $E$. camaldulensis were kindly provided by a plant taxonomist at the Faculty of Agriculture, Menoufia University. Extraction was done after washing leaves with tap water to remove dust. The extraction process was performed at the Faculty of Science, Menoufia University. Briefly, air-dried powdered leaves were soaked for three days in four liters of aqueous methanol $(85 \%)$ at room temperature $\left(25 \pm 2^{\circ} \mathrm{C}\right)$. The methanolic extract was concentrated in a rotational evaporator and the resulting extract was defatted with petroleum ether $\left(60-80^{\circ} \mathrm{C}\right)$ to obtain petroleum ether extract.

Killed vaccine preparation: Cercariae of $S$. mansoni were purchased from Schistosome Biological Supply Center (SBSC), Theodor Bilharz Research Institute. The E. camaldulensis extract was incubated with phosphate buffered saline-suspended cercaria in a dose of $10 \mathrm{mg} / 500$ cercaria for $30 \mathrm{~min}$ at room temperature (Mossalem et al, 2018). Killed cer- 
cariae were identified when they stopped movement completely for $1 \mathrm{~min}$. Killed cercariae were collected from the water using a $10 \mathrm{~mL}$ bacteriological loop, counted under dissecting microscope, re-suspended in PBS and became ready for use. Each mouse of GIII was immunized subcutaneously with 500 killed cercariae at the right flank (Hsu et al, 1981). A booster dose of 500killed cercaria was subcutaneously injected at right flank after 2 weeks of the $1^{\text {st }}$ immunization (Etewa et al, 2014).

Experimental infection by $S$. mansoni: The challenge infection was performed 30 days after the last immunization. Mice were infected by subcutaneous injection of 100 living Egyptian strain $S$. mansoni cercariae at the left flank (Peters and Warren, 1969).

Euthanizing mice and sample collection: Before challenge infection, blood samples were obtained by retroorbital sinus puncturing for all mice. Serum was separated by centrifugation of the collected blood samples at $3000 \mathrm{rpm}$ for $5 \mathrm{~min}$ and kept at $-20^{\circ} \mathrm{C}$ until use. 17 days post-infection (d.p.i.), mice of subgroup A were euthanized, blood was collected and serum was separated. Livers were perfused for schistosomula retrieval. 50d.p.i, those of subgroup B were euthanized, blood was collected to separate sera. Livers were perfused for retrieval of the adult worms then dissected into 2 parts. The first part was used for hepatic ova counting and the second part was preserved in $10 \%$ formalin for histopathological studies. Intestine (ileum) was removed and dissected for counting intestinal trapped ova. Retrieved schistosomula and adults were preserved in glutaraldehyde for SEM examination.

Schistosomula and adult loads: Schistosomula was retrieved from livers of subgroup A mice and adults were retrieved from the livers of subgroup B mice. This was done by normal saline perfusion of hepatic and porto-mesenteric vessels via cannulation of inferior vena cava of mice to count schistosomula, male, female, and coupled worms.

Tissue egg load: Samples of liver and int- estine were weighed and digested in $\mathrm{KOH}$ $5 \%$ for $16 \mathrm{hrs}$ at $37^{\circ} \mathrm{C}$, and ova were counted.

SEM of schistosomula and adults: Retrieved schistosomula and adults were fixed with $2.5 \%(\mathrm{v} / \mathrm{v})$ glutaraldehyde in PBS (phosphate buffer saline $),(\mathrm{pH}=7.4)$ for $24 \mathrm{hrs}$ at room temperature. They were rinsed three times with PBS before storage in PBS at $4^{\circ} \mathrm{C}$ until use. Before SEM, worms were washed twice with distilled water, dehydrated in ascending ethanol series, and critically point dried. They were put on aluminum stubs, sputtercoated with $20 \mathrm{~nm}$ gold nanoparticles, and examined in a high-resolution SEM (Jol $5200 \mathrm{lv}$, Japan) at an accelerating voltage of $5 \mathrm{kV}$ in Electron Microscope Unit, Faculty of Agriculture, Mansoura University.

Hematoxylin and eosin ( $\mathrm{H} \& \mathrm{E})$ staining of granuloma: Formalin fixed liver samples were paraffinized and stained with $\mathrm{H} \& \mathrm{E}$. The granulomas were counted, and diameters were digitally measured using a multihead microscope, Olympus SC100 and analyzed. Diameter of granuloma with a single ovum was only considered.

Assessment of serum levels of specific IgG, IgG1, IgG2a, IFN- $\gamma$ \& IL-10: Sera levels of specific IgG, IgG1, \& IgG2a were measured in serum samples by homemade ELISA technique (El-Aswad et al, 2019). Serum levels of IFN- $\gamma$ \&IL-10 were measured using a solid-phase sandwich ELISA which was purchased from Life Technologies Corporation, USA for IFN- $\gamma$ \& Abcam, USA for IL-10. Procedure was done according to the manufacturer's protocol. OD values were measured at $450 \mathrm{~nm}$ absorbance with an ELISA reader (Bio-Rad, UK).

Statistical analysis: Data were managed by SPSS statistical package version 23 (IBM windows); expressed as mean, median and standard deviation (SD). ANOVA test was used for comparison of quantitative variables between more than two groups of normally distributed data with Tuckey test as post Hoc test. Kruskal Wallis test was used to compare quantitative variables between more than two groups with Tamhane's test as 
post hoc test. Protection worm reduction was calculated (Tendler et al, 1986): $\mathrm{P}(\% \mathrm{R})=$ $\mathrm{C}-\mathrm{V} / \mathrm{C} \times 100$, whereas $\mathrm{P}=$ protection $\%, \mathrm{C}=$ mean parasites number recovered from infected mice and $\mathrm{V}=$ mean parasites number recovered from vaccinated one. Significance level was $95 \%, \mathrm{P}>0.05$ was not significant and $\mathrm{P}<0.05$ was significant.

\section{Results}

Schistosomula and adult male, female, couple, total worm load KCI immunized showed significant reduction $(84.14 \%, 70.37 \%$, $60.47 \%, 67.02 \%, \& 66.6 \%$, respectively; 3 $\&$ p4 $<0.001)$ in all parameters compared to non-immunized infected control (Tab. 1).

Reduced worm was in tissue egg load where KCI immunized one showed significant reduction $(65.35 \%, \& 63.77 \%$, respectively; p4 $<0.001)$ of ova counts in intestine and liver (Tab. 2).

Ultrastructural deformities: Adults in the KCI group showed lost tubercular spines, extensive tegmental damage, surface blebbing and cracking extended to suckers \& gynaecophoric canal, and females with furr- owing, surface cracking \& blebbing (Fig. 1).

Histopathological liver showed KCI with significant reduction $(60 \%, \& 64.73 \%$, respectively; $\mathrm{p}<0.001$ ) in granuloma number and dimeter compared to non-immunized infected control (Tab., 3 \& Fig. 2).

Activation of humoral immune response in $\mathrm{KCI}$ immunized mice was higher than nonimmunized infected controls. Serum levels of IgG, IgG1 \& IgG2a showed significant differences ( $\mathrm{p} 3 \& \mathrm{p} 4<0.001$ as compared to infected controls at all times (Fig. 3).

IFN- $\gamma$ levels in KCI group showed a highly significant initial increase following the booster dose and at early phase of challenge infection $(17$, d.p.i.), then started to decrease in last challenge infection phase $(50$, d.p.i) with significantly higher $(\mathrm{p} 3 \& \mathrm{p} 4<0.001)$ than the infected control group. Anti-inflammatory cytokine, IL10 levels raised after booster dose and 17 d.p.i., continued to increase to late phase of challenge in KCI with significant differences (p3 \& p4 <0.001) as compared with infected control group at all times (Fig. 4).

Table 1: Comparison between worm load in all groups:

\begin{tabular}{|c|c|c|c|c|c|c|c|}
\hline Variables & Groups & $\mathrm{N}$ & $\overline{\mathrm{x}} \pm \mathrm{SD}$ & Median & Reduction \% & p-value & Post Hoc Test \\
\hline \multirow{3}{*}{ Schistosomula } & GIa (-ve control) & 10 & $0.0 \pm 0.0$ & 0.0 & \multirow{3}{*}{84.14} & \multirow{3}{*}{$<0.001^{* *}$} & $\mathrm{p} 1<0.001^{* *}$ \\
\hline & $\mathrm{GIIa}(+\mathrm{ve}$ control) & 10 & $8.20 \pm 0.78$ & 8.0 & & & $\mathrm{p} 2<0.001 * *$ \\
\hline & GIIIa (KCV) & 10 & $1.30 \pm 0.94$ & 1.0 & & & $\mathrm{p} 3<0.001^{* *}$ \\
\hline \multirow{3}{*}{ Males } & GIb (-ve control) & 10 & $0.0 \pm 0.0$ & 0.0 & \multirow{3}{*}{70.37} & \multirow{3}{*}{$<0.001 * *$} & $\mathrm{p} 4<0.001 * *$ \\
\hline & GIIb (+ve control) & 10 & $5.40 \pm 0.84$ & 6.0 & & & p5 $<0.001 * *$ \\
\hline & GIIIb (KCV) & 10 & $1.60 \pm 1.42$ & 2.0 & & & p6 <0.001** \\
\hline \multirow{3}{*}{ Females } & GIb (-ve control) & 10 & $0.0 \pm 0.0$ & 0.0 & \multirow{3}{*}{60.47} & \multirow{3}{*}{$<0.001 * *$} & $\mathrm{p} 4<0.001^{* *}$ \\
\hline & GIIb (+ve control) & 10 & $4.30 \pm 0.67$ & 4.0 & & & $\mathrm{p} 5<0.001 * *$ \\
\hline & GIIIb (KCV) & 10 & $1.70 \pm 1.25$ & 2.0 & & & p6 <0.001** \\
\hline \multirow[b]{3}{*}{ Couples } & GIb (-ve control) & 10 & $0.0 \pm 0.0$ & 0.0 & \multirow{3}{*}{67.02} & \multirow{3}{*}{$<0.001 * *$} & $\mathrm{p} 4<0.001 * *$ \\
\hline & GIIb (+ve control) & 10 & $9.40 \pm 0.69$ & 9.50 & & & p5 $<0.001 * *$ \\
\hline & GIIIb (KCV) & 10 & $3.10 \pm 1.52$ & 3.0 & & & p6 <0.001** \\
\hline \multirow[b]{3}{*}{ Total worms } & GIb (-ve control) & 10 & $0.0 \pm 0.0$ & 0.0 & \multirow{3}{*}{66.6} & \multirow{3}{*}{$<0.001 * *$} & $\mathrm{p} 4<0.001 * *$ \\
\hline & GIIb (+ve control) & 10 & $19.10 \pm 0.34$ & 19.50 & & & p5 <0.001** \\
\hline & GIIIb (KCV) & 10 & $6.40 \pm 2.01$ & 7.00 & & & $\mathrm{p} 6<0.001^{* *}$ \\
\hline
\end{tabular}

p1: compared between GIa \& GIIa. p2: compared between GIa \& GIIIA. p3: compared between GIIa \& GIIIa. p4: compared between GIb \& GIIb.p5: comparison between GIb \& GIIIb. p6: compared between GIIb \& GIIIb.

Table 2: Comparison between tissue egg load in all groups:

\begin{tabular}{|c|c|c|c|c|c|c|c|}
\hline Variables & Groups & No. & $\overline{\mathrm{x}} \pm \mathrm{SD}$ & Median & Reduction \% & p-value & Post Hoc Test \\
\hline \multirow{3}{*}{$\begin{array}{l}\text { Intestinal } \\
\text { egg count }\end{array}$} & GIb (-ve control) & 10 & $0.0 \pm 0.0$ & 0.0 & \multirow[t]{3}{*}{65.35} & \multirow[t]{3}{*}{$<0.001 * *$} & $\mathrm{p} 4<0.001 * *$ \\
\hline & GIIb (+ve control) & 10 & $4820.0 \pm 595.91$ & 4950.0 & & & $\mathrm{p} 5<0.001^{* *}$ \\
\hline & GIIIb $(\mathrm{KCV})$ & 10 & $1670.0 \pm 526.62$ & 1750.0 & & & p6 <0.001** \\
\hline \multirow{3}{*}{$\begin{array}{l}\text { Hepatic egg } \\
\text { count }\end{array}$} & GIb (-ve control) & 10 & $0.0 \pm 0.0$ & 0.0 & \multirow[t]{3}{*}{63.77} & \multirow[t]{3}{*}{$<0.001 * *$} & $\mathrm{p} 4<0.001^{* *}$ \\
\hline & GIIb (+ve control) & 10 & $7623.60 \pm 1069.87$ & 8000.0 & & & p5 $<0.001^{* *}$ \\
\hline & GIIIb (KCV) & 10 & $2761.70 \pm 586.76$ & 2750.0 & & & p6 $<0.001 * *$ \\
\hline
\end{tabular}

p4: compared between GIb \& GIIb.p5: comparison between GIb \& GIIIb. p6: compared between GIIb \& GIIIb. 
Table 3: Comparison between mean number and diameter of liver granulomas in all groups:

\begin{tabular}{|c|c|c|c|c|c|c|c|}
\hline Granuloma & Groups & No. & $\overline{\mathrm{x}} \pm \mathrm{SD}$ & Median & Reduction \% & p-value & Post Hoc Test \\
\hline \multirow[b]{3}{*}{ Number } & GIb (-ve control) & 10 & $0.0 \pm 0.0$ & 0.0 & \multirow[t]{3}{*}{60} & \multirow[t]{3}{*}{$<0.001 * *$} & $\mathrm{p} 4<0.001^{* *}$ \\
\hline & GIIb (+ve control) & 10 & $10.80 \pm 2.14$ & 10.0 & & & p5 $<0.001 * *$ \\
\hline & GIIIb (KCV) & 10 & $4.33 \pm 0.70$ & 4.0 & & & p6 <0.001** \\
\hline \multirow{3}{*}{ Diameter } & GIb (-ve control) & 10 & $0.0 \pm 0.0$ & 0.0 & \multirow[t]{3}{*}{64.73} & \multirow[t]{3}{*}{$<0.001 * *$} & $\mathrm{p} 4<0.001 * *$ \\
\hline & GIIb (+ve control) & 10 & $319.00 \pm 39.28$ & 325.0 & & & p5 $<0.001 * *$ \\
\hline & GIIIb $(\mathrm{KCV})$ & 10 & $112.50 \pm 10.06$ & 112.50 & & & $\mathrm{p} 6<0.001^{* *}$ \\
\hline
\end{tabular}

p4: compared between GIb \& GIIb.p5: comparison between GIb \& GIIIb. p6: compared between GIIb \& GIIIb.

\section{Discussion}

In the present study, the killed cercariae were chosen to overcome the disadvantages of live attenuated cercaria vaccination especially the unsafety of radiation (Kariuki et al, 2006). A common natural killing agent was used to be safe, of low cost and easily administered by the target population (Todd and Colley, 2002). The methanolic extract of E. camaldulensis was chosen as the cercariakilling agent because it approved efficacy in killing cercaria in canal water and was recommended to be used in control programs of schistosomiasis (Ghareeb et al, 2018).

In the present study, high reduction was recorded by the immunogen $\mathrm{KCI}$, either in schistosomula or adult worm loads exceeded $60 \%$ that enabled a good vaccine candidate. Deborah et al. (2001) considered a 25\% reduction of worm load was sufficient for a good immunogen vaccine candidate. Nascimento et al. (2002) found that a good vaccine was to achieve more than $40 \%$ of worm load reduction. So, worm load reduction was standard point for an efficient vaccine (McManus and Loukas, 2008). Efficiency of cercarial antigen homogenates in immunization against $S$. mansoni was proved. Ashour et al. (2004) reported an immuno-prophylactic effect of the cercarial antigens, CAP with $42 \%$ worm burden reduction. Soliman et al. (2008) found that worm reduction with CAP was $53.8 \%$ due to eggs reduction post immunization. Etewa et al. (2014) tested the CAP with 2 types of adjuvants, BCG and Freund's and a worm load reduction was $56.02 \%$ \& $51.85 \%$, respectively with reduction of eggs.

The significant reduction of the tissue ova counts, either intestinal or hepatic, explained the reduced adults especially in coupled that subsequently decreased the eggs deposition (Fallon and Dunne, 1999). Also, gynecophoric canal deformities with abnormal matting and decreased egg deposition (Steinauer, 2009). The reduced tissue egg load reduced hepatic granulomas number and size (Chitsulo et al, 2004) a vaccine caused even a partial reduction in worm burdens and pathogenesis, and Ashour et al. (2004) reported improvement of liver enzymes post CAP immunization. The KCI was regarded as a significant activation of both wings of the immune system, humoral and cellular (Jankovic et al, 1999). The present significant increase of the specific total IgG, IgG1 \& IgG2a explained the reduction of worm load since generated antibodies interfered with the important functions of the parasite surface molecules, alkaline phosphatase. Inhibition molecule interfered with adult tegument repair rendering it liable to destructive attacks of the host immune system (Fallon et al, 1994).

In the present study, the fluctuations of IgG1 \& IgG2a levels reflected the prevailing lymphocyte type because IgG2a, a marker of Th1 lymphocyte activation and IgG1 reflected a $\mathrm{Th} 2$ response. In the early phase of challenge (17, d.p.i.), IgG2a levels showed more increase reflection of Th1 predominance. The reverse occurred in the late challenge phase (50, d.p.i.) withe more increase in IgG1 that reflected Th2 predominance. This agreed with Pearce and MacDonald (2002). So, KCI potentiated the immune response with more killing of immature \& mature stages of $S$. mansoni. Th1\& Th2 lymphocytes potent activation protected the infective phases, the important character of a good vaccine (McManus and Loukas, 2008).

In the present study, the predominant Th1 detected in the early phase of challenge was 
associated with increased IFN- $\gamma$ that decreased gradually to the experimental end. This proved that the anti-schistosomula properties of KCI because IFN- $\gamma$ initiated leucocyte adhesion-forming foci in the lungs with subsequent delayed migration of schistosomula (Wilson et al, 1996), and stimulated recuritment and activation of pulmonary macrophages to kill schistosomula (Jankovic et al, 1999).

The gradual increase of Th2 predominance explained the increased levels of Th2cytokine, IL-10 that continued to increase till the challenge late phase (Sadler et al, 2003). This can be one of the causes of decreased hepatic pathology and decreased size of hepatic granulomas as IL-10 prevented the Th1 \& Th2-mediated pathologies (ElAhwany et al, 2012). So, maintained a nonlethal chronic infection and prevented inappropriate immune responses (Stephenson et al, 2014).

\section{Conclusion}

The outcome results showed that Eucalyptus camaldulensis-killed cercariae and immunogen decreased the severity of challenge Schistosoma mansoni infection. Its action spectrum involved both schistosomula and adult worms.

The protective mechanism included activation of immune response in a similar cascade to natural infection. It induced a mixed Th1 and Th2 responses with enhanced humoral immune response.

\section{Acknowledgments}

The authors sincerely appreciate Dr. Asmaa Shams El Dein, Department of Pathology for her kind support in liver histopathological examination.

\section{References}

Anisuzzaman, T, Sujic, N, 2020: Schistosomiasis and hookworm infection in humans: Disease burden, pathobiology and anthelmintic vaccines. Parasitol. Inter. 75:102051.

Ashour, AA, Ahmed, SA, Maghraby, AS, Zahran, HG, 2004: Immunoprophylactic effect of single and mixed schistosomal antigens on Schistosoma mansoni infected mice. Egypt. J. Hos. Med. 14:86-103.
Batish, DR, Singh, HP, Kohli, RK, Kaur, S, 2008: Eucalyptus essential oil as a natural pesticide. Forest Ecol. Manag. 256:2166-74.

Carvalho, IT, Stevinho, BN, Santos, L, 2016: Application of microencapsulated essential oils in cosmetic and personal healthcare products, a review. Int. J. Cosm. Sci. 38:109-19.

Chitsulo, L, Engels, D, Montresor, A, Savioli, L, 2000: The global status of schistosomiasis and its control. Acta Trop. 77, 1:41-51.

Chitsulo, L, Loverde, P, Engels, D, 2004: Schistosomiasis. Nat. Rev. Microbiol. 2, 1:12-3.

Deborah, S, Rebecca, TH, Ruth, A, 2001: The 14-3-3 protein as a vaccine candidate against schistosomiasis. Parasit. Immunol. 23:213-7.

Dias SR, Boroni, M, Rocha, EA, Dias, TL, Souza, DL, et al, 2014: Evaluation of the Schistosoma mansoni Y-box-binding protein (SMYB1) potential as a vaccine candidate against schistosomiasis. Front. Genet. 5:174.

El Ridi, R, Tallima, H, 2015: Why the radiation-attenuated cercarial immunization studies failed to guide the road for an effective schistosomiasis vaccine: A review. J. Adv. Res. 6:255-67. El-Ahwany, E, Bauiomy, IR, Nagy, F, Zalat, R, Mahmoud, O, et al, 2012: Regulatory cell respons- es to immunization with a soluble egg antigen in Schistosoma mansoni-infected mice. Korean J. Para-sitol. 50, 1:29-35.

El-Aswad, BEW, Harba, NM, Moharm, IM, Mahmoud, SF, 2019: Immunization with adult Schistosoma mansoni tegument, treated with sub-curative praziquantel, partially protects mice against the infection. J. Helminth. 94:1-12.

Etewa, SE, Abd El-Aal, NF, Abdel-Rahman, SA, El-Shafey, MA, 2014: Parasitological evaluation of potential candidate vaccines in Schistosoma mansoni-infected mice. J. Parasitol. Vect. Biol. 6, 2: 23-30.

Fallon, PG, Smith, P, Nicholls, T, Modha, J, Doenhoff, MJ, 1994: Praziquantel-induced exposure of Schistosoma mansoni alkaline phosphatase: drug-antibody synergy which acts preferentially against female worms. Parast. Immunol. 16:529-35.

Fallon, PG, Dunne, DW, 1999: Tolerization of mice to Schistosoma mansoni egg antigens causes elevated type 1 and diminished type 2 cytokine responses and increased mortality in acute infection. J. Immunol. 162, 7:4122-32

Ghareeb, MA, Habib, MR, Mossalem, HS, Abdel-Aziz, MS, 2018: Phytochemical analysis 
of Euc-alyptus camaldulensis leaves extracts and testing its antimicrobial and schistosomicidal activities. Bull. Nat. Res. Cent. 42:16-9.

Hsu, SYL, Hsu, HF, Burmeister, LF, 1981: Schistosoma mansoni: Vaccination of mice with highly X-irradiated cercariae. Exp. Parasitol. 52: 91-104.

Jankovic, D, Wynn, TA, Kullberg, MC, Hieny, S, Caspar P, et al, 1999: Optimal vaccination against Schistosoma mansoni requires the induction of both B cell- \& IFN gamma-dependent effector mechanisms. J. Immunol. 162:345-51.

Kariuki TM, Van Dam GJ, Deelder AM, Farah IO, Yole DS, et al, 2006: Previous or ongoing schistosome infections do not compromise the efficacy of the attenuated cercaria vaccine. Infect. Immun. 2006: 3979-86.

Keitel, WA, Potter, GE, Diemert, D, Bethony, J, El Sahly, HM, et al, 2019: A phase 1 study of the safety, reactogenicity, and immunogenicity of a Schistosoma mansoni vaccine with or without glucopyranosyl lipid A aqueous formulation (GLA-AF) in healthy adults from a non-endemic area. Vaccine 37:6500-9.

Leow, CY, Willis, C, Chuah, C, Leow, CH, Jones, M, 2020: Immunogenicity, antibody responses and vaccine efficacy of recombinant annexin B30 against Schistosoma mansoni. Parasit. Immunol. 2020:e12693. doi:10.1111/pim. 12693 Lotfy, WM, Hishmat, MG, El Nashar, AS, Abu El-Einin, HM, 2015: Evaluation of a method for induction of praziquantil resistance in Schistosoma mansoni. Pharm Biol. 53, 8:1214-9

McManus, DP, Loukas, A, 2008: Current status of vaccines for schistosomiasis. Clin. Microbiol. Rev. 21, 1:225-42.

Mossalem, HS, Habib, MR, Ghareeb, MA, 2018: Control of infection of Biomphalaria alexandrina (Ehrenberg, 1831) with Schistosoma mansoni Sambon, 1907 using Eucalyptus camaldulensis. Folia Malacol. 26, 3:155-65.

Nascimento, E, Leão, IC, Pereira, VR, Gomes, YM, Chikhlikar, P, et al, 2002: Protective immunity of single and multi-antigen DNA vaccines against schistosomiasis. Mem. Inst. Oswaldo Cruz 97: 1105-9.

Neelam, A, Hany, O, Sherwani, SK, Jabeen, S, Nangyal, H, 2014: phytochemical and bioactivity of commercially available Eucalyptus oil against human pathogens. South Asian J. Life Sci. 2:8-11.

Nerio, LS, Olivero-Verbel, J, Stashenko, E,
2010: Repellent activity of essential oils: a review. Biores. Technol. 101:372-8.

Omar, A, Elmesallamy, Gel-S, Eassa, SJ, 2005: Comparative study of the hepatotoxic, genotoxic $\&$ carcinogenic effects of praziquantel distocide $\&$ the natural myrrh extract Mirazid on adult male albino rats. J. Egypt. Soc. Parasitol. 35, 1:31329.

Pearce, EJ, James, SL, 1986: Post lung-stage schistosomula of Schistosoma mansoni exhibit transient susceptibility to macrophage-mediated cytotoxicity in vitro that may relate to late phase killing in vivo. Parasit. Immunol. 8, 5:513-27.

Pearce, EJ, MacDonald, AS, 2002: The immunobiology of schistosomiasis. Nat. Rev. Immunol. 2: 499-511.

Peters, AP, Warren, KS, 1969: A rapid method of infecting mice and other laboratory animals with Schistosoma mansoni subcutaneous injection. J. Parsitol. 55:558-63.

Pino, JA, Marbot, R, Quert, R, Garcia, H, 2002: Study of essential oils of Eucalyptus resinifera, E. tereticornis and Corymbia maculata (Hook.) grown in Cuba. Flav. Frag. J. 17:1-14.

Rofatto, HK, Araujo-Montoya, BO, Miyasato, PA, Levano-Garcia, J, Rodriguez, D, et al, 2013: Immunization with tegument nucleotidases associated with a subcurative praziquantel treatment reduces worm burden following Schistosoma mansoni challenge. Peer J 1:e58.

Rostamian, M, Bahrami, F, Niknam, H, 2018: Vaccination with whole-cell killed or recombinant leishmanial proteinand toll-like receptor agonists against Leishmania tropica in BALB/c mice. PLoS One 13, 9:0204491.

Sadler, CH, Rutitzky, LI, Stadecker, MJ, Wilson, RA, 2003: IL-10 is crucial for the transition from acute to chronic disease state during infection of mice with Schistosoma mansoni. Eur. J. Immunol. 33:880-8.

Shuxian, L, Guangchen, S, Donald, X, Manus, M, Hotez, PJ, 1998: Progress in the development of a vaccine against schistosomiasis in China: A review. Inter. J. Infect. Dis. 2, 3:176-8.

Soliman, MF, El Shenawy, NS, El Arabi, SE, 2008: Schistosoma mansoni: melatonin enhances efficacy of cercarial and soluble worm antigens in the induction of protective immunity against infection in the hamster. Exp. Parasitol. 119, 2:291-5.

Steinauer, ML, 2009: The sex lives of parasites: Investigating the mating system and mecha- 
nisms of sexual selection of the human pathogen Schistosoma mansoni. Int. J. Parasitol. 39, 10: 1157-63.

Stephenson, R, You, H, McManus, D, Toth, I, 2014: Schistosome vaccine adjuvants in preclinical and clinical research. Vaccines (Basel) 2, 3: 654-85.

Strugnell, R, Zepp, F, Cunningham, A, Tantawichien, $T$, 2011: Vaccine antigens: Understanding modern vaccines: Perspect. Vaccinol. 1, 1: 61-88.

Tebeje BM, Harvie M, You H, Loukas, A, McManus, DP, 2016: Schistosomiasis vaccines: where do we stand? Parast. Vec. 9:528-32.
Tendler, M, Pinto, RM, Oliveira, LA, Gebara, G, Katz, N, 1986: Schistosoma mansoni: Vaccination with adult worm antigens. Int. J. Parasitol. 16, 4:347-52.

Todd, CW, Colley, DG, 2002: Practical and ethical issues in the development of a vaccine against schistosomiasis mansoni. Am. J. Trop. Med. Hyg. 66, 4:348-58.

Wilson, RA, Coulson, PS, Betts, C, Dowling, MA, Smythies, LE, 1996: Impaired immunity and altered pulmonary responses in mice with a disrupted interferon- $\gamma$ receptor gene exposed to the irradiated Schistosoma mansoni vaccine. Immunol. 87:275-82.

\section{Explanation of figures}

Fig.1: SEM micrograph of S. mansoni adults of KCI group: a- Anterior part of male worm showed deformed suckers (referred by red arrow), blebs (referred by yellow arrow) and surface depressions (referred by green arrow), b- Male tegument showed deformed tubercles with lost spines (referred by green arrow), blebs (referred by yellow arrow) and depressed or ruptured tubercles (referred by green arrow), c- Gynecophoric canal showed widening, roughness (referred by green arrow) and blebs (referred by yellow arrow), and d- Female worm showed rough surface and blebbing (referred by yellow arrow), irregularity (referred by green arrow) and furrowing (referred by red arrow).

Fig. 2: H \& E stained liver tissue: a- Small sized granuloma of KCI group (referred by yellow arrow) surrounding a single S. mansoni ovum (referred by green arrow), and b-Large sized granuloma of infected control group (referred by yellow arrow) surrounding a single S. mansoni ovum (referred by green arrow).

N.B. scale bar $=100 \mu \mathrm{m}$.

Fig. 3: Comparison between groups regarding serum levels: a- $\operatorname{IgG}$ after 2 nd booster dose of KCV, 17 d.p.i. and also, 50 d.p.i., b- IgG1 after 2 nd booster dose of KCV, 17 d.p.i. and also, 50 d.p.i, and c- IgG2a after 2nd booster dose of KCV, 17 d.p.i. and also, 50 d.p.i.

Fig. 4: Comparison between groups regarding serum levels: a- IFN- $\gamma$ after 2 nd booster dose of KCV, 17 d.p.i. and also, 50 d.p.i, and b- IL10 after 2 nd booster dose of $\mathrm{KCV}, 17$ d.p.i. and also, 50 d.p.i.

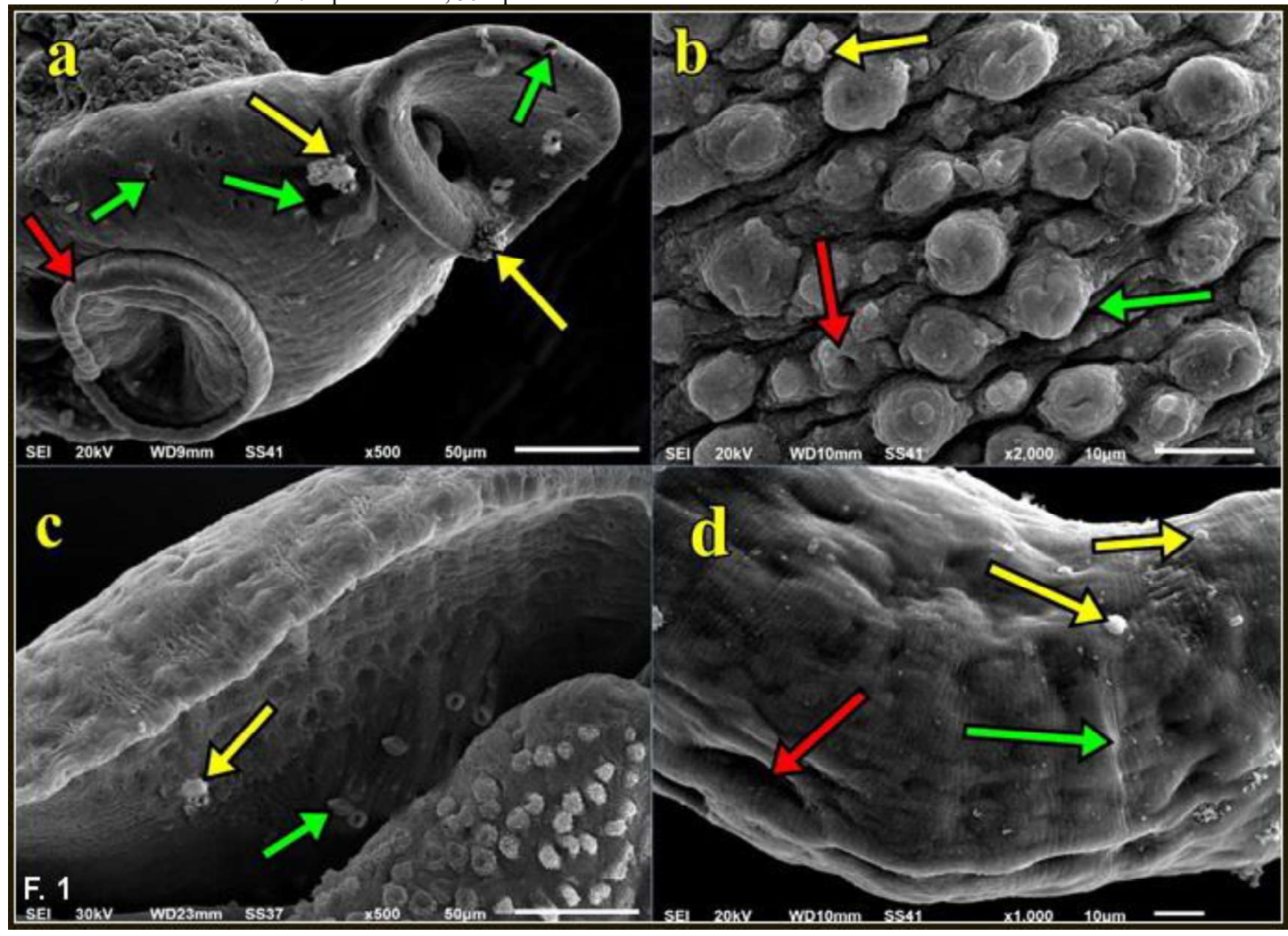



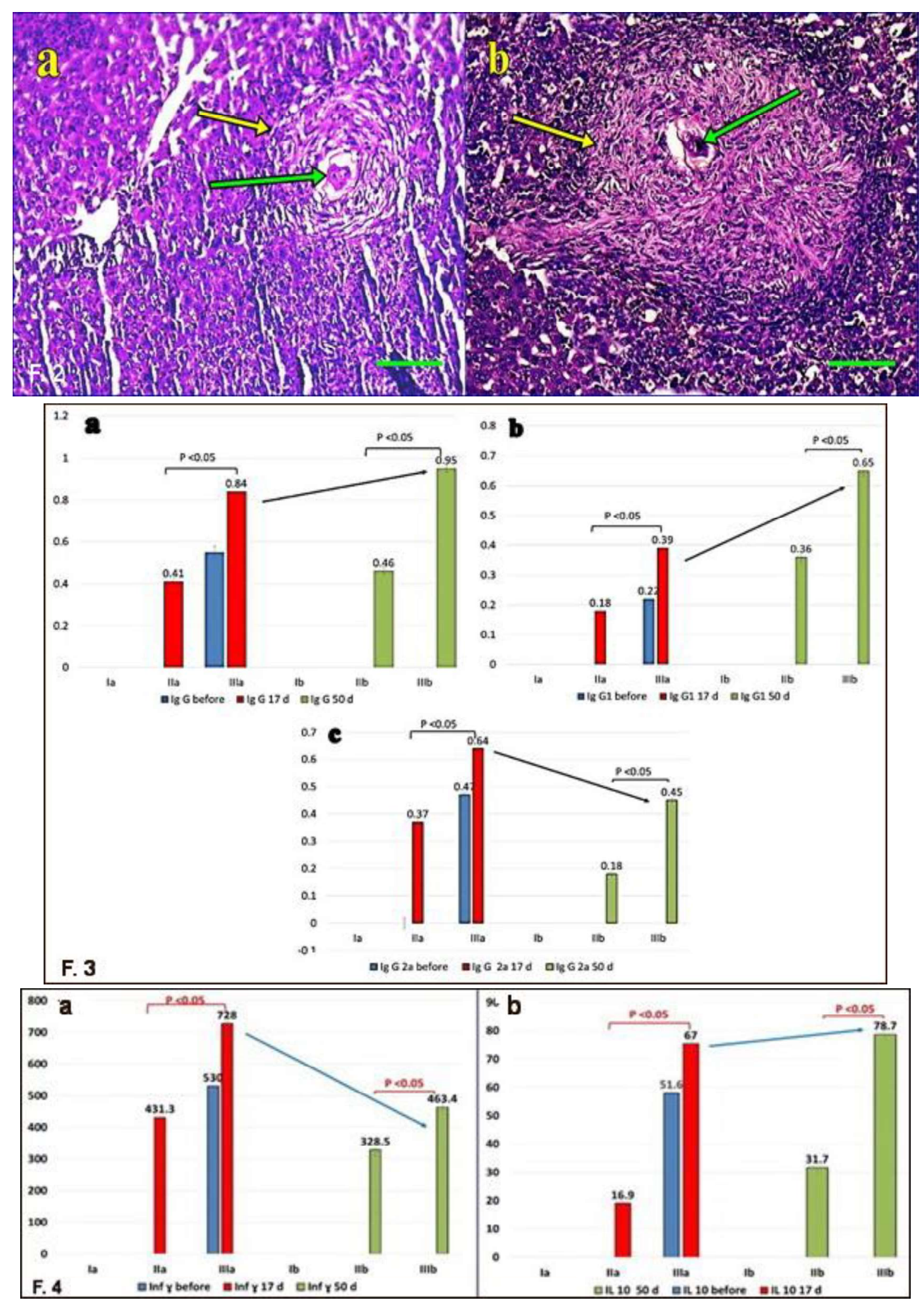